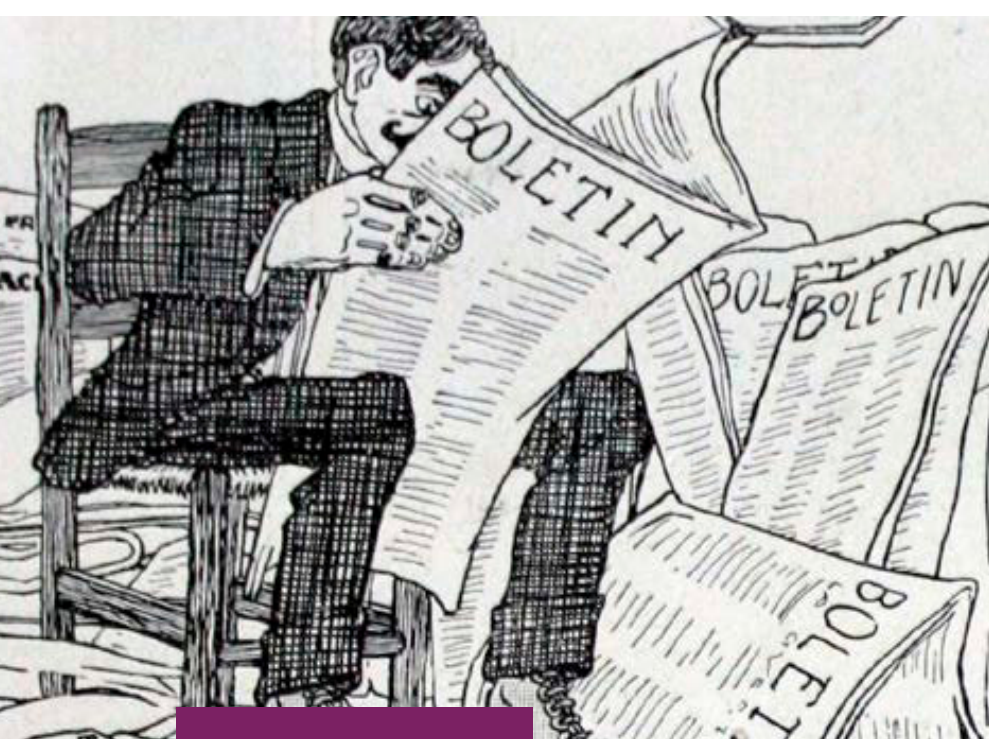

FIGURAS REVISTA ACADÉMICA DE INVESTIGACIÓN

ISSN 2683-2917

Vol. 2, núm. 1, noviembre 2020-febrero 2021

https://doi.org/10.22201/fesa.figuras.2020.2.1

Esta obra está bajo una licencia

Creative Commons Atribución-NoComercial-

Compartirlgual 4.0 Internacional

\section{Dimensiones de la cultura literaria en México (1800-1850). Modelos de sociabilidad, materialidades, géneros y tradiciones intelectuales}

\section{Dimensions of the literary culture in Mexico (180o-1850). Models of sociability, materialities, genres and intellectual traditions}

https://doi.org/10.22201/fesa.figuras.2020.2.1.135

Gamaliel Valentín-González

Universidad Nacional Autónoma de México, Facultad de Filosofía y Letras

El libro que se reseña es el primero de seis volúmenes que integran la colección Historia de las literaturas en México, proyecto impulsado por diferentes instituciones pertenecientes a la Universidad Nacional
Autónoma de México (UNAM). El conjunto de 18 ensayos expone los múltiples factores que influyeron en la conformación de la cultura literaria mexicana durante la primera mitad del siglo XIX a partir de las investigaciones de diversos especialistas, cuyos trabajos se caracterizan por su pluralidad de enfoques donde el hilo conductor es dar una visión global que explique el sistema literario mexicano en un marco contextual amplio que problematice diferentes vetas del conocimiento.

\section{Nuevas rutas}

Un grueso libro de más de quinientas páginas y forros color turquesa salta a la vista del lector. Tras leer su título, resulta llamativo el texto que la portada lleva al calce: Historia de las literaturas en México. Siglo XIX. El sólo nombre echa a andar nuestra mente para preguntarnos por los actores y corrientes que guían el devenir de un titánico esfuerzo intelectual y editorial como el que tenemos enfrente. Dimensiones de la cultura literaria en México (180o-1850). Modelos de sociabilidad, materialidades, géneros y tradiciones intelectuales $^{1}$ es el primero de seis volúmenes que nos lleva a conocer y redescubrir la trama que ha dado forma a las letras nacionales, desde la víspera de la Independencia hasta los albores del presente siglo. La coordinación general de la serie estuvo a cargo de la doctora Mónica Quijano Velasco; en tanto que la doctora Esther Martínez Luna, especialista del periodo, asumió la responsabilidad de dar forma a este trabajo que a un tiempo contiene la raigambre y los primeros frutos de nuestras letras nacionales.

1 Esther Martínez Luna, coord., Dimensiones de la cultura literaria en México (180o-1850). Modelos de sociabilidad, materialidades, géneros y tradiciones intelectuales (Ciudad de México: UNAM, Coordinación de Humanidades, Instituto de Investigaciones Filológicas, Instituto de Investigaciones Bibliográficas, Facultad de Filosofía y Letras, 2018). 


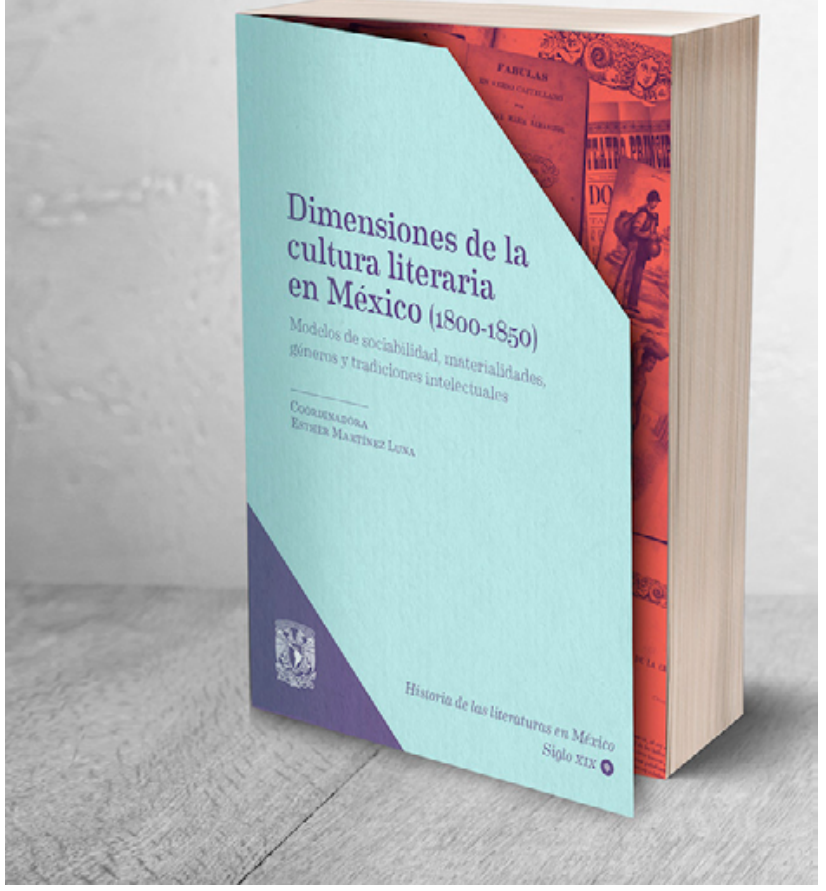

La respuesta a la pregunta inicial que hemos formulado halla razón en el tamiz de la corriente historiográfica fundada por los franceses Marc Bloch y Lucien Febvre, la Escuela de los Annales, cuyo método privilegia el estudio de los procesos sociales y los entes que provocan o derivan los grandes sucesos. Lo anterior, si bien no se menciona en las páginas del libro, se intelige a partir de su estructura y de la manera de abordar cada tema. En ese sentido, Dimensiones de la cultura literaria en México no es un simple repaso o enumeración de corrientes, géneros, nombres de autores y obras consolidadas; sino que centra su campo de estudio en reconocer y señalar las interacciones culturales que debieron existir durante la primera mitad del siglo xIx para sentar los cimientos de lo que hoy conocemos como literatura mexicana.

El libro se compone de 18 ensayos agrupados en cinco secciones (que pueden resultar ejes temáticos) con los siguientes títulos: "Los orígenes de la era mediática", los "Editores, impresos y agrupaciones", los "Modelos de sociabilidad y formación del público lector", los "Géneros literarios" y la "Herencia clásica". El contenido de los textos no es consecutivo en el tiempo, pues lo que se desea mostrar es una perspectiva que explique el desarrollo de los proce- sos literarios en México y cómo éstos se articulan a partir de la relación entre distintos actores y mecanismos, tanto sociales y políticos como culturales y estéticos durante los primeros cincuenta años del siglo XIX. Asimismo, además de los ensayos, se incluye una sección llamada "Discusión", donde se responde a preguntas nodales que caracterizaron la literatura del periodo.

Por su parte, la introducción, titulada "La explicación de la historia en materia literaria" de Esther Martínez Luna, expone los criterios y la metodología que siguió en la conformación del libro, además de contextualizar cultural y literariamente los temas que se abordan a lo largo del volumen.

Enseguida abre el diálogo el importante relato del quehacer de los primeros cotidianos, como la Gazeta de México y el Diario de México, semilleros del debate nacional y palestra intelectual de la sociedad de su tiempo. En contraparte, de igual manera se exploran "impresos menores" - loterías, hojas sueltas, calendarios- que buscaban satisfacer necesidades populares. Sigue una relación de obras llevadas a la estampa que fueron proscritas, condenadas a la clandestinidad por la Inquisición; una aproximación a las Bibliothecas de Eguiara y Eguren y Beristáin de Souza; el recuento de la encomiable función de impresores -Mariano Galván, José Mariano Lara, Ignacio Cumplido, entre otros similares- y el papel de la cultura impresa como impulsor de intelectuales y el nacimiento de la Arcadia de México y la Academia de Letrán. La literatura infantil, la nueva sociabilidad letrada de los llamados "currutacos" y la risa como esencia de la literatura también tienen lugar. No se deja de lado el estudio de géneros como la poesía, la siempre controvertida - por sus características constitutivas- novela corta, el teatro, la crónica de espectáculos ni el México que imaginaron y ayudaron a imaginar los viajeros de la época. Cierran el diálogo un trío de trabajos sobre tradición y oralidad, recepción de las lenguas clásicas y traducción de los escritores grecolatinos. 


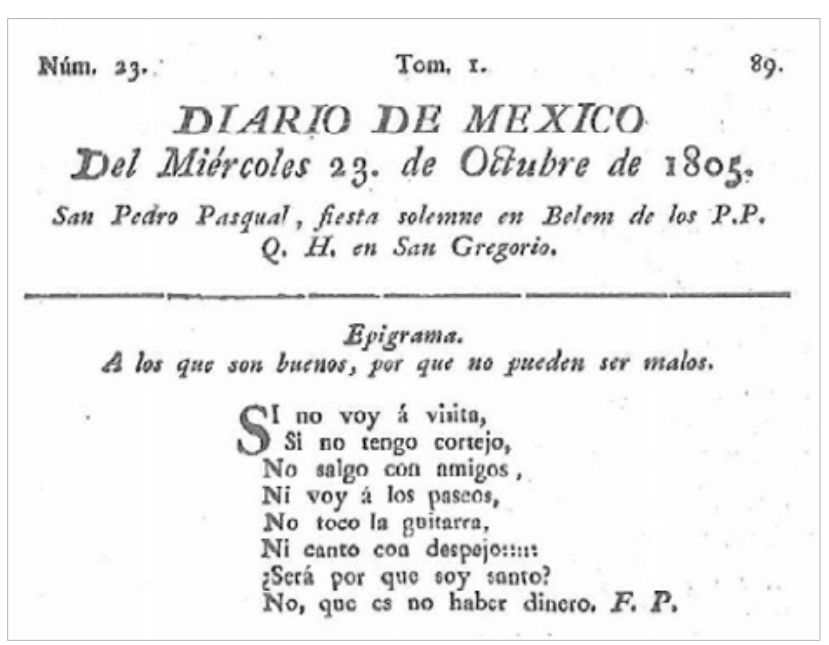

Diario de México. t. I. $n^{\circ}$ 23. Ciudad de México: Imprenta de doña María Fernández de Jáuregui, 1805. Hemeroteca Nacional Digital de México.

Sin duda, otro aspecto que refleja el influjo de la Escuela de los Annales es el planteamiento de preguntas que buscan contextualizar el asunto en turno para darle su justa dimensión, sin juicios anacrónicos a priori. A este respecto, el libro se cuestiona tanto el lugar social y la función de la retórica, depositaria de géneros y modelos de escritura, así como el lugar que los escritores asignaron a la literatura en los primeros años de la centuria decimonónica. De manera complementaria, una extensa cronología que incluye biblio-hemerografía, campos literarios, protagonistas, sucesos culturales, vida cotidiana y avances tecnológicos se despliega a nuestros ojos cual mapa que sirve para extender la vista más allá de los horizontes de un objeto de estudio, permitiendo comprender de mejor modo los entresijos de un tiempo de intensos cambios políticos y sociales.

La metodología historiográfica empleada en $\mathrm{Di}$ mensiones de la cultura literaria en México es de agradecerse, pues aplicar una visión cultural y social -donde intervienen impresores, editores, autores, público, redes y grupos de sociabilidad-, al campo de las letras, "rompe" con los esquemas que tienden a compendiar mucho de lo que ya se ha conceptualizado; por ejemplo, colocando una tras otra a las corrientes literarias y encasillando obras y autores de acuerdo con etiquetas preestablecidas, cual si de co- locar libros en su anaquel correspondiente se tratara. Un gran acierto, para rebatir lo anterior, ha sido dejar que sean los especialistas de distintas instituciones universitarias -quienes a menudo están más próximos a las fuentes de estudio- los que escriban, sin importar su nacionalidad, porque la tradición se ha construido gracias a los vínculos con el mundo entero. Como ya lo dijo el maestro Alfoso Reyes: "La única manera de ser provechosamente nacional consiste en ser generosamente universal". ${ }^{2}$ Es singular que, en el esfuerzo de historizar, los investigadores formen parte de la historia misma a través de páginas que lo mismo servirán a sus pares que a estudiantes e interesados en la materia.

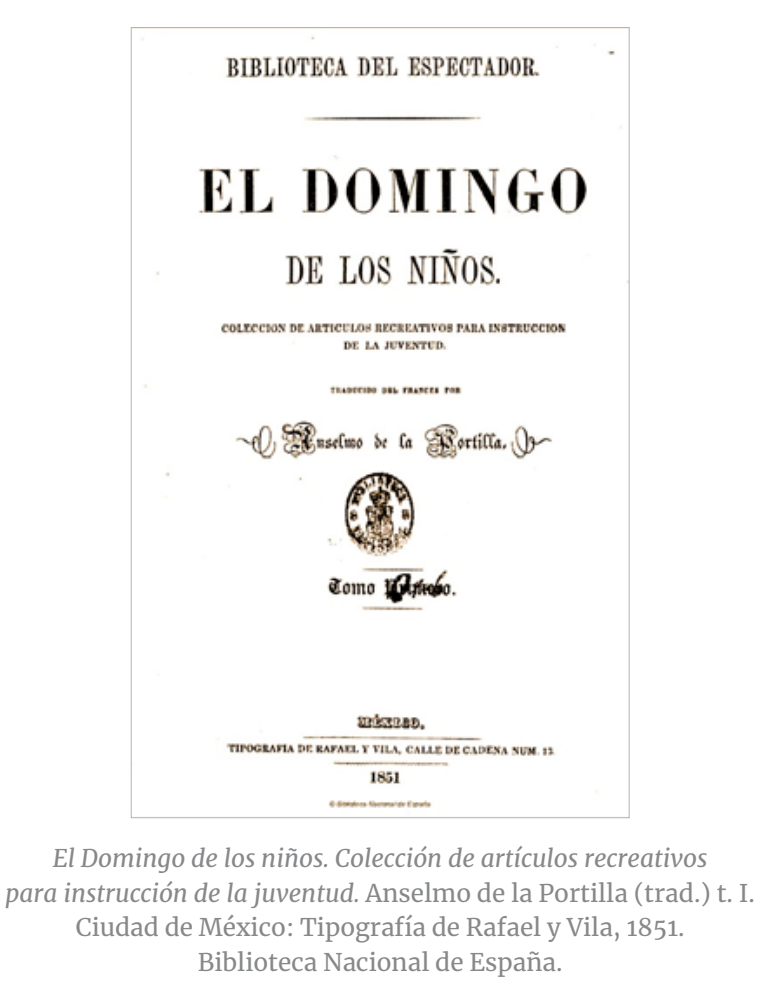

En esta obra sin desperdicio, sería difícil ahondar en unos ensayos más que en otros; no obstante, digna de señalarse, dentro de la pluralidad de voces que podemos escuchar, es la relevancia otorgada a la

2 Alfonso Reyes, Obras completas VIII: Tránsito de Amado Nervo, De viva voz, A lápiz. Tren de ondas, Varia (México: Fondo de Cultura Económica, 1996). 
literatura infantil, las aportaciones de los viajeros extranjeros que echaron raíces en México y el oficio de traductor (autor poco reconocido incluso hoy). En el ensayo "En busca del niño lector: trazas de literatura infantil en el México independiente" se estudia la infancia "como un concepto en construcción", no de algo ya establecido que inspirara la creación de materiales exclusivos para los infantes, al tiempo que se toman como referencia para su explicación la historia de la lectura, del libro y de la educación.

Por su parte, en "La patria de mis viajes. México en el imaginario de los primeros viajeros" se brinda relevancia a las visitas de Joel Roberts Poinsett, C.C. Becher, Isidore Löwenstein y la marquesa Calderón de la Barca en la construcción de la idea de México que tendrían propios y extraños en los años por venir, y que buena luz han dado sobre nuestro pasado. Destaca, por ejemplo, el arribo en 1803, de Alexander von Humboldt, junto con Aimé Bonpland, y la redacción de su Ensayo político sobre el Reino de la Nueva España, indispensable documento que despertó la curiosidad de medio mundo.

En cuanto a "La traducción de los clásicos grecolatinos", se demuestra que no hay generación espontánea en el campo de las artes. Mal que les pese a algunos, la herencia cuenta, lo mismo en la creación literaria que en el porte con que se conducen los individuos en la esfera pública.
Finalmente, el proyecto Historia de las literaturas en México felizmente viene a trazar nuevas rutas de interés e investigación con un trabajo de carácter no monolítico, a partir de la presentación de aspectos poco atendidos y que hallan su piedra de toque - por sus miras a los años coloniales y a la formación de una nueva identidad- en Dimensiones de la cultura literaria (1800-1850). Modelos de sociabilidad, materialidades, géneros y tradiciones intelectuales, empresa que pone en altorrelieve las líneas escritas en la prensa que poco a poco fueron consolidándose en la creación de asociaciones literarias, la redacción de novelas por entregas y ensayos de obras que sólo el tiempo pondría en su lugar. De esta manera, se deja constancia de que la cultura escrita ha sido y sigue siendo una actividad multidisciplinaria en la que importan las ideas y el papel en que se plasman. Bienvenida sea esta nueva historia escrita.

\section{Referencias}

Martínez Luna, Esther, coord. Dimensiones de la cultura literaria en México (180o-1850). Modelos de sociabilidad, materialidades, géneros y tradiciones intelectuales. Ciudad de México: UNAM, Coordinación de Humanidades, Instituto de Investigaciones Filológicas, Instituto de Investigaciones Bibliográficas, Facultad de Filosofía y Letras, 2018.

Reyes, Alfonso. Obras completas VIII: Tránsito de Amado Nervo, De viva voz, A lápiz. Tren de ondas, Varia. México: Fondo de Cultura Económica, 1996.

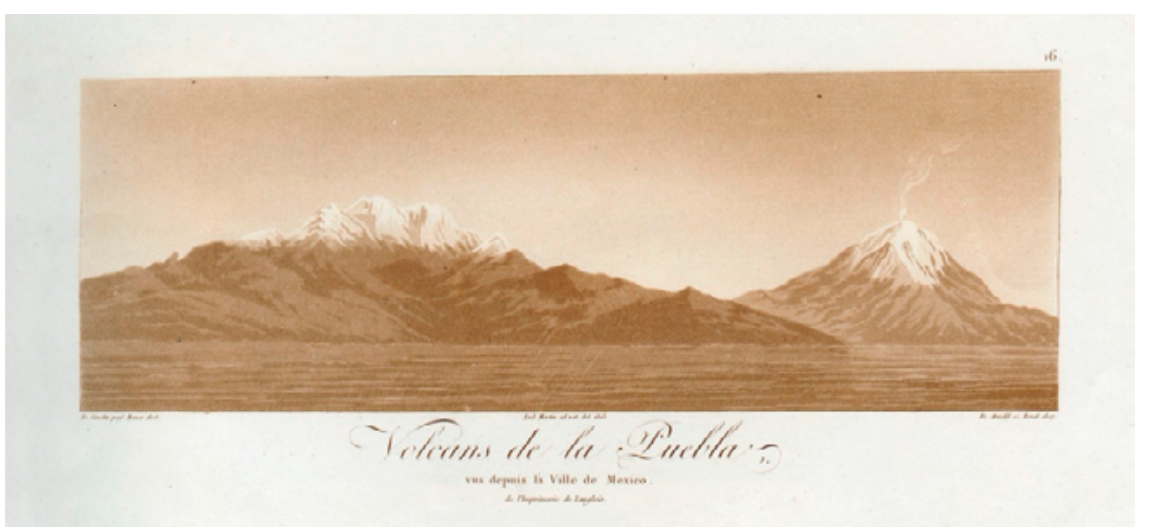

"Volcanes de Puebla vistos desde el valle de México, dibujados por F. Gmelin en Roma y grabados en Berlín por F. Arnold, a partir de un boceto de don Luis Martín realizado en México", en Alexander von Humboldt. Atlas géographique et physique du royaume de la Nouvelle Espagne, fondé sur des observations astronomiques, des mesures trigonométriques et des nivellemens barométriques. Paris: De l'imprimerie de J.H. Stone, 1811. Acervo del Museo Franz Mayer. 